\title{
A RETROSPECTIVE STUDY OF BORDERLINE OVARIAN TUMOURS
}

\author{
Nirmala. C, Ava D. Desai, Shilpa M. Patel, Kalpana S. Dave
}
1. Fellow, Department of Obstetrics \& Gynaecology, Gujarat Cancer and Research Institute, New Civil Hospital campus, Asarva, Ahmedabad.
2. Professor \& Unit Head, Department of Obstetrics \& Gynaecology, Gujarat Cancer and Research Institute, New Civil Hospital campus, Asarva, Ahmedabad.
3. Associate Professor, Department of Obstetrics \& Gynaecology, Gujarat Cancer and Research Institute, New Civil Hospital campus, Asarva, Ahmedabad.
4. Professor \& HOD, Department of Obstetrics \& Gynaecology, Gujarat Cancer and Research Institute, New Civil Hospital campus, Asarva, Ahmedabad.

\section{CORRESPONDING AUTHOR}

Dr. Nirmala. C,

No.449, 8 th main,

I T I layout, Malathahalli,

Bangalore-560065

E-mail: nimc80@yahoo.com

Ph: 00918722525901

ABSTRACT: OBJECTIVE(S): To study patient characteristics, histopathology, management, recurrence and survival in borderline ovarian tumours. METHOD(S): Thirteen patients with borderline ovarian tumours treated at GCRI during 2000-2005, were analyzed retrospectively for the above features. RESULTS: Mean age at diagnosis was 41.3 years. Complete surgery was done in eleven and conservative surgery in three. Eleven (84.61\%) had stage I, one (7.69\%) stage IIIC while one (7.69\%) was unstaged. Frozen section correlated in 50\% mucinous and $20.5 \%$ serous tumours. Two patients had recurrence, at six and nine years. One underwent secondary cytoreduction; followed by observation alone. The second unresectable recurrence was given salvage chemotherapy. CONCLUSION(S): Patients with borderline ovarian tumours have excellent survival and prognosis compared to epithelial ovarian cancers. Stage of the tumour is a prognostic indicator for recurrence. Conservative surgery is relatively safe and can be advocated in women of reproductive age, but only after thorough counseling about the increased risk of recurrence. Frozen section diagnosis of borderline ovarian tumours is inaccurate.

KEY WORDS: Borderline ovarian tumours, fertility preserving surgery, frozen section diagnosis

INTRODUCTION: Patients with borderline ovarian tumours are younger and present more often with early stage disease compared with those with invasive ovarian cancer, hence the significance of fertility preserving surgery. These patients have a high survival rate making prolonged follow up an essential component. Recurrences may develop even after a latent period of 20-50 years. Primary disease or recurrence is treated by optimal surgical cytoreduction.

METHODS: Thirteen patients with borderline ovarian tumours treated between 2000- 2005 at GCRI, Ahmedabad were analysed retrospectively. The standard surgical procedure was staging laparotomy with total abdominal hysterectomy with bilateral salphingo oophorectomy with 
bilateral pelvic lymph node dissection and infracolic omentectomy done in ten patients. Appendicectomy was done in one patient with mucinous tumour. Two patients underwent fertility preserving surgery. The tumour was sent for frozen section in six patients. The following parameters were analysed: Age, parity, symptoms, stage, post operative residual tumour, histologic type, adjuvant treatment, recurrence and survival. The accuracy of frozen section diagnosis was determined by its comparison with the final histopathological diagnosis. Patients were regularly followed up with clinical examination, abdomino pelvic ultrasound, chest X ray, Ca-125 every six months for the first two years and yearly thereafter.

RESULTS: The mean age at diagnosis was 41.3 years with ten patients less than 45 years of age. Five were post menopausal, eight in the reproductive age group. Two were nulligravida and 11 were parous.

Six patients presented with ascitis and palpable mass, four with pain abdomen, one each with post menopausal bleeding, anorexia and anuria. One patient was asymptomatic and was detected during a routine gynecological examination. On ultrasound, mean maximum diameter of mucinous tumours was $32 \mathrm{~cm}$ compared to $13 \mathrm{~cm}$ in serous tumours.

Three patients underwent fertility preserving surgery. One was a nulligravida with stage IA disease, underwent a staging laparotomy with left sided salphingo oophorectomy. She conceived spontaneously during the six year disease free period. The other patient was also a nulligravida, with stage IB disease. She underwent a staging laparotomy with bilateral ovarian cystectomy. She conceived spontaneously during the seven year disease free period. The third patient was unstaged and had primary fertility preserving surgery elsewhere. She presented at GCRI nine years later with recurrence and underwent a left side ovarian tumour removal with total abdominal hysterectomy with bilateral pelvic lymph node dissection and infracolic omentectomy. No adjuvant therapy was given and the patient was closely followed up. Disease free survival was two years following the cytoreductive surgery (Table 2).

Frozen section diagnosis of borderline tumours correlated with the final histopathological report in $50 \%$ of mucinous and $20.5 \%$ of serous histology (Table 3 ).

Six patients (46.15\%) had mucinous and seven (53.84\%) had serous tumours. Among patients with mucinous tumors, five were unilateral (83.33\%) and one was bilateral $(16.66 \%)$. Serous tumours were unilateral in five $(71.42 \%)$ and bilateral in two $(28.57 \%)$ patients.

Eleven patients $(84.61 \%)$ presented with stage I disease, nine with stage IA disease and two with stage IB disease, one (7.69\%) with stage IIIC disease, and one (7.69\%) was unstaged. Patients with stage I disease underwent total abdominal hysterectomy with bilateral salphingo oophorectomy with bilateral pelvic lymph node dissection and infra colic omentectomy. They received no adjuvant treatment and were followed up regularly. Adjuvant treatment with six cycles of cisplatin and cyclophosphamide were given in one patient with stage IIIC disease. The last patient underwent fertility preserving surgery elsewhere and was unstaged as mentioned above. Recurrence was noted in two patients. One patient had stage IIIC mucinous tumour of borderline malignancy. She underwent complete surgery, received adjuvant chemotherapy. She presented six years later with inoperable disease with liver metastasis and was treated with three cycles of Paclitaxel and Carboplatin. No response was noted and oral palliative Etoposide and Tamoxifen was prescribed for three months. The second recurrence was noted in the unstaged patient as mentioned above (Table 4). 
DISCUSSION: The mean age group of patients in the present study is 41.3 years. It is lower than that reported by other authors for patients with borderline ovarian tumours. The age group of these patients is less than that of patients with invasive carcinomas (median -55 years).

Sutton et al reported that the mean age of the patients in their study was 48 years (1).

In the current study, $84.61 \%$ (11 patients) had stage I disease, $7.69 \%$ (1 patient) had stage III disease, and $7.69 \%$ (1 patient) was unstaged. As the patients were reported to have borderline tumours, no adjuvant treatment was given in those with stage I disease.

Burgmann et al studied 193 patients with low malignant potential tumours who underwent conservative surgery for the same. Majority of them had stage I disease (97\%) (2). The majority of borderline tumours in this study were of serous histology (53.8\%).

Eltabbakh et al reported that among the 32 women with borderline ovarian tumours, $23(71.9 \%)$ had serous and nine (28.1\%) had mucinous histology (3).

In the present study, mucinous and serous tumours were unilateral in $16.6 \%$ and $71.42 \%$ of the patients respectively. Mucinous tumours tended to be larger than serous tumours. Kaern et al concluded that the mucinous tumours were significantly larger than the serous tumours. Mucinous tumours tend to be unilateral due to their larger size as compared to the serous tumours ${ }^{(4)}$.

In our case series, there was one patient with stage IIIC disease with associated borderline mucinous cystadenocarcinoma of the appendix and pseudomyxoma peritonei. The role of chemotherapy even in IIIC disease is controversial. However, six cycles of cisplatin and cyclophosphamide as adjuvant chemotherapy was given due to extensive disease. She developed recurrence six years later with unresectable disease and liver metastasis. The stage at presentation (IIIC) and the presence of pseudomyxoma peritonei place her at high risk for recurrence. The role of chemotherapy cannot be concluded from this study.

Casey et al studied six patients with advanced stage who received post operative chemotherapy for borderline ovarian tumours. Only two of these four patients who underwent second laparotomy had residual disease, suggesting a role for chemotherapy in advanced stage (5).

In the current study, recurrences were noted in two patients. The first patient presented with stage IIIC disease of mucinous borderline ovarian tumours as mentioned above. The second was an unstaged patient who had primary conservative surgery else where. The recurrence rate for stage IIIC disease and fertility preserving surgery is $10 \%$ and $33.3 \%$ respectively. Overall recurrence rate is $15.38 \%$ which is in agreement with the other studies. The stage of disease (IIIC) in one and conservative surgery in the other are high risk factors for recurrence. Hence long term follow up is necessary in these patients.

Zanetta et al noted five recurrences of borderline tumours (stage II and stage III disease). The clinical recurrence rate was $15.2 \%$ (25 of 164) in stage I after conservative surgery, 2.5\% (3 of 119) in stage I after radical surgery, 40\% (10 of 25 ) in stage II or III after conservative surgery and $12.9 \%$ (4 of 31 ) in stage II or III after radical surgery (6).

In the current study, three patients underwent conservative surgery. One was a nulligravida with stage IA mucinous tumour. She underwent a staging laparotomy with left sided salphingo oophorectomy. She conceived spontaneously during the six year disease free period. The second also was a nulligravida, with bilateral serous tumours (stage IB). She underwent a staging laparotomy with bilateral ovarian cystectomy. She conceived spontaneously during the seven year disease free period. The third was an unstaged patient who had a primary fertility preserving surgery (Right side salphingo oophorectomy) elsewhere. The clinical recurrence rate 
following conservative surgery was $33.3 \%$ while $10 \%$ after complete surgery. Hence the rate of recurrence was three times higher in women treated by conservative surgery as compared to those treated by complete surgery. This suggests a role for ovarian conservation in women with stage I disease with increased risk of recurrence explained to the patient and relatives.

A retrospective study was conducted by Burgmann et al where 193 patients underwent conservative surgery for borderline tumours. Rate of recurrence was three times higher in women who were treated by cystectomy (23\%) compared to women who were treated by unilateral salphingo oophorectomy (7\%) ${ }^{(3)}$.

In the current study, the frozen section diagnosis of borderline malignancy correlated with final histopathological diagnosis in $30.3 \%$ of cases, $50 \%$ of mucinous and $20.5 \%$ of serous histology. Thus frozen section is inaccurate in the diagnosis of borderline tumours. Patients and their relatives have to be explained about the need for a re-laparotomy in case the final histopathology report suggests invasion.

According to Menzin A W et al, of the 48 cases with an intra operative frozen section diagnosis, 32 (67\%) were correctly identified. A frozen section evaluation of borderline ovarian tumour is thus accurate in excluding benign pathology (7).

In the current study, survival was $100 \%$ in patients with stage I disease. Zanetta et al reported that the disease free survival by stage is $99.6 \%$ (276 of 277) for stage I, 95.8\% (23 of 24 ) for stage II, and $89 \%$ (25 of 28 ) for stage III disease (6).

CONCLUSION(S): Patients with borderline ovarian tumours have excellent survival and prognosis compared to epithelial ovarian cancers. Stage of the tumour is a prognostic indicator for recurrence. Conservative surgery is relatively safe and can be advocated in women of reproductive age, but only after thorough counseling about the increased risk of recurrence. Frozen section diagnosis of borderline ovarian tumours is inaccurate.

\section{REFERENCES:}

1. Sutton G P, Bundy B N, Omura G A,Yordan E L, Beecham J B, Bonfiglio T. Stage III Ovarian tumours of low malignant potential treated with Cisplatin combination therapy (A Gynecologic oncology Group study). Gynecol. Oncol. 1991; 41: 230-233.

2. Burgmann E S, Long term outcomes following conservative surgery for borderline ovarian tumour of the ovary: A large population based study. Gynecol. Oncol. 2006; 103: 841-847.

3. Eltabbakh G H, Natarajan N, Piver M S, Mettlin C J. Epidemiologic differences between women with borderline ovarian tumours and epithelial ovarian cancer. Gynecol. Oncol. 1999; 74: 103-107.

4. Kaern J., Trope C G., Abeler V M. Retrospective study of 370 borderline ovarian tumours treated at the Norwegian Radium hospital from 1970-1982. CANCER 1993; 71: 1810-20.

5. Casey A C, Bell D A, Lage J M, Fuller A F, Nikrui N, Rice L W. Epithelial Ovarian tumours of borderline malignancy: Long term follow up. Gynecol. Oncol. 1993; 50: 316-322.

6. Zanetta G, Rota S, Chiari S, Bonazzi C, Bratina G, Mangioni C. Behaviour of borderline tumours with particular interest to persistence, recurrence and progression to invasive carcinoma: A prospective study. J. Clin. Oncol. 2001; 19: 2658-2664.

7. Menzin A W, Rubin S C, Noumoff J S, Livolsi V A. Gynecol. Oncol. 1995; 59: 183-185. 
Table 1: Fertility preserving surgery

\begin{tabular}{|c|c|c|c|c|c|c|}
\hline $\begin{array}{l}\text { Age } \\
\text { (yrs) }\end{array}$ & Parity & Surgery & Place of surgery & Stage & HPE & $\begin{array}{l}\text { Obstetric } \\
\text { history }\end{array}$ \\
\hline 20 & $\begin{array}{l}\text { Nulli } \\
\text { gravida }\end{array}$ & Staging + LSO & GCRI & IA & $\begin{array}{l}\text { Mucinous } \\
\text { Unilateral }\end{array}$ & conceived \\
\hline 22 & $\begin{array}{l}\text { Nulli } \\
\text { gravida }\end{array}$ & $\begin{array}{l}\text { Staging + bilateral } \\
\text { ovarian } \\
\text { cystectomy+ } \\
\text { bilateral ovarian } \\
\text { preservation }\end{array}$ & GCRI & IB & $\begin{array}{l}\text { Serous } \\
\text { Bilateral }\end{array}$ & conceived \\
\hline 42 & P1L1 & $\begin{array}{l}\text { RSO } \\
\text { Secondary } \\
\text { cytoreduction }\end{array}$ & $\begin{array}{l}\text { Elsewhere } \\
\text { GCRI }\end{array}$ & Unstaged & $\begin{array}{l}\text { Serous } \\
\text { papillary }\end{array}$ & - \\
\hline
\end{tabular}

LSO- left side salphingo oophophorectomy

RSO- right side salphingo oophophorectomy

Table 2: Accuracy of frozen section diagnosis

\begin{tabular}{|l|l|l|l|}
\hline $\begin{array}{l}\text { Final HP } \\
\text { report }\end{array}$ & \multicolumn{3}{|l|}{ Frozen section diagnosis (n=12) } \\
\hline $\begin{array}{l}\text { Mucinous } \\
\text { BOT }\end{array}$ & Benign & Borderline & Malignant \\
\hline 6 & 1 & 3 & 2 \\
\hline Serous BOT & & & \\
\hline 6 & 3 & 1 & 2 \\
\hline
\end{tabular}


Table 3: Post-operative management

\begin{tabular}{|l|l|l|l|l|l|}
\hline No & Stage & Surgery & Adjuvant Rx & Recurrence & Follow up \\
\hline 1 & IA & FS & - & - & NED-6y \\
\hline 2 & IIIC & CS & $\begin{array}{l}\text { Cisplatin+ } \\
\text { Cyclophosphamide } \\
\text { (6 cycles) }\end{array}$ & $\begin{array}{l}\text { Paclitaxel+Carboplatin } \\
\text { (3 cycles) }\end{array}$ & A \\
\hline 3 & IA & CS & - & - & NED (1y) \\
\hline 4 & IA & CS & - & - & NED (6y) \\
\hline 5 & IA & CS & - & - & NED (5m) \\
\hline 6 & IA & CS & - & - & NED (3m) \\
\hline 7 & IA & CS & - & - & L \\
\hline 8 & IA & CS & - & - & NED (5m) \\
\hline 9 & IB & CS & - & - & NED (3y) \\
\hline 10 & IA & CS & - & - & L \\
\hline 11 & IB & FS & - & - & NED (7y) \\
\hline 12 & IA & CS & - & - & NED (3y) \\
\hline 13 & Unstaged & $\begin{array}{l}\text { FS else } \\
\text { where }\end{array}$ & - & CS at GCRI & recurrence) \\
& & & & & \\
\hline
\end{tabular}

CS- 10, FS- 3; NED-10, L-2, AWD - 1

CS- complete surgery; FS- fertility sparing; NED- No evidence of disease; L- lost to follow up; AWD- alive with disease; $y$ - years, $m$ - months 